\title{
Sistema educativo em \\ Moçambique: as estratégias internacionais de inclusão
}

- Sistema educativo en Mozambique: as estrategias de
inclusión internacional

- Educational system in Mozambique: international inclusion strategies

Mirian Célia Castellain Guebert ${ }^{1}$

Mariano Araujo Rodrigues ${ }^{2}$

Resumo: Este artigo tem o objetivo de auxiliar na compreensão de como são implementadas as estratégias internacionais de inclusão no sistema educativo em Moçambique. O estudo tem como base teórica Freire (2014); Rosa (1998/2004); Brandão (1986); Bolacha (2013); Chambal (2007); Rodrigues (2008) incluindo as recomendações da UNESCO (1990) e o Plano Estratégico Para Educação De Moçambique (PEE 1998-2003). A escolha dessas publicações se deu devido ao alto grau de representatividade na implantação do sistema educativo inclusivo em Moçambique, que consiste a centralidade da educação como a força de mudança, instrumento de superação das barreiras de exclusão e a construção da cidadania, potencializando a conquista do ser sujeito na vida social. Quanto à metodologia, utilizou-se da pesquisa documental, que viabilizou o entendimento do contexto histórico, econômico,

1 Doutora em Educação, História, Política, Sociedade pela PUC- São Paulo. Professora do Programa de Pós-graduação em Direitos Humanos e Políticas Públicas na PUC do Paraná. Professora convidada da Universidade Católica de Moçambique, no Doutorado de Humanidade. mirian.guebert@gmail.com

2 Doutorando em Humanidades - Direitos Humanos - Universidade Católica de Moçambique, Faculdade de Ciências Sociais e Políticas - Quelimane. marianoaraujorodrigues@gmail.com 
educacional e social de Moçambique. Para a realização das análises foram considerados os pressupostos defendidos nos documentos internacionais para a implementação da inclusão escolar, sustentada por uma análise do contexto. Das constatações se pode afirmar que a educação inclusiva é um direito social e a sua promoção é de responsabilidade do Estado. Essa educação deve ser acompanhada por ações que impactem de forma direta a vida do cidadão, numa estratégia gradual, contínua e sistemática, sendo oferecida a todos, independentemente de suas características físicas, econômica, sociais e ou culturais. Em outras palavras, o Estado deve garantir um processo educacional de qualidade, que amplie as relações intersociais, por meio de práticas pedagógicas alicerçadas no princípio da equidade para superação de toda e qualquer dificuldade que se interponha à construção de uma escola democrática. Nesse sentido a educação inclusiva, contribui na edificação de uma sociedade justa, livre de preconceitos como forma de promover a dignidade humana.

Palavras-chave: Educação em Moçambique. Educação inclusiva. Direitos humanos.

Resumen: Este artculo tiene o objetivo de ayudar a compreender cómo se implementan las estrategias inclusión internacional el sistema educativo em Mozambique. El estúdio se basa teóricamente Freire (2014); Rosa (1998/2004); Brandão (1986); Bolacha (2013); Chambal (2007); Rodrigues (2008) incluidas as recomendaciones de la UNESCO (1990) y el Plan Estratégico Para Educación en Mozambique (PEE 1998-2003). La elección de estas publicaciones se debi[o al alto grado de representación del sistema educativo inclusivo em Mozambique, que consiste em la centralidad de la educación como a fuerzade cambio, um instrumento de superar las barreras de la exclusión y la construcción de ciudadanía, potenciando el logro del ser sujeto em la vida social. Em cuanto a la metodologia, se utilizo la investigación documental, que permitiócompreender el contexto histórico, económico, educativo e social de Mozambique. Para la realización de las análisis se consideraron los supuestos formulados em los documentos internacionales para la implementación de la inclusão escolar, apoyadas em um analisis del contexto. De los hallazgos se puede decir que la educación inclusiva es un derecho social y su promoción es responsabilidad del Estado. Esta Educación debe ir acompañada de acciones que impacten diretamente em la vida del ciudadano, em uma estrategia gradual, continua y sistemática, ofreciéndose a todos, independentemente de sus características físicas, económica, sociales o culturales. Es decir, el Estado debe garantizar un processo educativo de calidad, que amplíe las relaciones inter- 
sociales, a través de prácticas pedagógicas basadas em el princípio da equidad para superar todas y cada uma de las dificultades que se interponem em el caminho de la construcción de uma escuela democrática. Es este sentido, la Educación inclusiva, contribuye a la construción de una sociedade justa, libre de prejuicios como forma de promover la dignidad humana.

Palabras clave: Educación em Mozambique. Educación inclusiva. Derechos humanos

\begin{abstract}
This work ains understand how they are implemented as international strategies for inclusion in the Education suystem in Mozambique, having as basis Freire (2014), Rosa (2004), Brandão (1986), Bolacha (2013); Chambal (2007); Rodrigues (2008), and recomendation from UNESCO (1990) and Strategic Education Plan for Moçambique PEE (1998-2003). The choice of these publications was due to the high degree of representativeness in the implementation of the inclusive Educational sytem in Mozambique, which consists of the centrality of education as the force for change, and instrument for overcoming the barriers of exclusion and the construction of citizenship, enhancing the conquest of your being subject in social life. As for the employee, it uses documentar research, which as a natural source of information, made it possible to understand the historical, economic, Educational and social context of Mozambique. Inorder to carry out the analyzes, the assumptions of inclusion supported by na analysis of the contexto were considered. From the findings it can be said that inclusive education is a social rights and promotion the resposibility of the State, it must be accompanied by actions that directly impact the life of the Citizen, in a gradual, continuous, systematic way, being offered to all regardless of their physical, economic, social and cultural characteristics, that is must open students with disabilities, guaranteeing a quality Educational porcess, which expands inter-social relations guarantes a teaching practic with principles of equily to overcome any all difficulties thea stands in the way of Building a democratic Scholl. Whitin the scope of na inclusive education, contributes to the Building of a just Society, free from prejudice as a way promoting human dignity.
\end{abstract}

Keywords: Education in Mozambique, Inclusive education, Human rights. 


\section{Introdução}

Neste trabalho são abordadas as questões relacionadas à implementação das estratégias internacionais de inclusão no sistema educacional de Moçambique. Este texto é um recorte da tese de doutorado em Humanidades da Universidade Católica de Moçambique.

A proposta da reflexão abre espaço para a contextualização do quotidiano educacional no país, com vistas à construção de uma sociedade inclusiva, capaz de construir relações sociais mais justas, solidárias sedimentadas na garantia de direitos.

De acordo com Bueno (2005, p. 1), após a promulgação da Declaração de Salamanca, o tema da inclusão escolar passou a estar na ordem do dia, quer seja nas perspectivas das propostas políticas nacionais e internacionais, quer no discurso dos políticos de todos os matizes ideológicos, quer nas ações concretas dos governantes e de muitas escolas (ou de todas, mesmo que obrigadas), quer nas produções cientificas acadêmica e de cunho técnico profissional.

O princípio da inclusão é um valor social e consiste no reconhecimento da necessidade de se caminhar rumo à escola para todos: lugar que acoIhe e reconhece todos nas diferenças, desenvolve aprendizagens e responde às necessidades individuais. Para que isso seja realidade, a escola deve estar aberta para receber, respeitar e comunicar-se com todos os seus membros da comunidade, a fim de atender com coerência e consciência as especificidades a quem se destina, efetivando a construção gradativa e permanente do processo educacional inclusivo.

Convém ressaltar que os protocolos internacionais, dos quais Moçambique faz parte, indicam os princípios das políticas de inclusão escolar entendidas a partir do que significa exclusão, que, por sua vez, está relacionada à problemática social, descrita em uma perspectiva dual do dentro e fora, aceito e não aceito.

Ao considerar o desenvolvimento da sociedade, seguida das políticas sociais do Estado, entende-se que a inclusão social efetiva-se quando as pessoas reconhecem e vivem os direitos e deveres perante o contrato social. Nessa perspectiva, a pessoa incluída é aquela que usufrui dos direitos sociais, sendo a educação um desses direitos. Por outro lado, expressa uma concepção, para o enfretamento da problemática social que impõe ao cidadão compor um grupo que responde ao modelo social estabelecido.

A sociedade inclusiva é aquela que reconhece todos como cidadãos de direito, portanto, o sistema educacional, que visa à formação de cidadão, cabe a cada país identificar as possibilidades de implementação deste princípio no contexto nacional.

Hobbes (2002) entende que, no estado civil, as pessoas tornam-se ci- 
dadãs e, como cidadãs, estão submetidas ao poder do soberano. Mas a preservação do homem enquanto indivíduo (o bem privado) é algo que vai além de sua posição enquanto cidadão.

Rousseau (2003), por sua vez, destaca que o fundamental de uma boa educação é fomentar nas pessoas o prazer de amar as ciências e seus métodos. Para ele a educação deve desenvolver o conhecimento do homem, como essência e ao mesmo tempo ética, ou seja, um homem ideal para a sociedade que deveria integrar-se.

Para compreender como são implementadas as estratégias internacionais de inclusão no sistema educativo em Moçambique, faz-se necessário considerar que educação constitui a base de formação do homem, capaz de atuar em benefício da sociedade da qual ele faz parte. Ao mesmo tempo, garante a este homem os seus direitos básicos à vida, reconhecidos para o cidadão, de modo universal e interdependente.

A educação é o critério essencial na formação da ética para viver a cidadania; este é um dos desafios do processo educativo na sociedade contemporânea, visto que educar não é apenas instruir, mas oferecer experiências significativas que preparem o cidadão para a vida na sociedade.

Neste sentido, Moçambique, como subscritor das estratégias internacionais de inclusão, é chamado a criar condições para que todas as pessoas sintam-se livres de qualquer forma de discriminação, por meio da promoção de atitudes e valores fundamentais como o respeito às diferenças e diversidades, 0 acolhimento e a promoção dos direitos dos cidadãos, especialmente no que concerne ao direito social de educação para todos.

A política educativa moçambicana define a educação básica como um direito universal. Porém, a opção que o país fez, para efetivar uma concepção de escolas inclusivas, coloca desafios nos diferentes segmentos, econômicos, jurídicos e educacionais, no que se refere à criação de condições estruturais, conceituais e humanas, para garantir que todas as pessoas que demandem desses processos inclusivos sejam atendas.

Para a implementação do processo educacional inclusivo, segundo as recomendações internacionais, são necessários: infraestruturas adequadas, para atender a diversidade; alocação de materiais; programas de formação inicial e continuada junto aos profissionais da educação. Dessa forma, será possível promover com sucesso a educação inclusiva, entendida como uma questão de direitos humanos pelo fato de: defender que a diferença identifica-nos; por considerar a igualdade e a dignidade inerente a todo ser humano; por ser expressão do processo formativo, que busca a igualdade e a formação cidadã e que incluir deve ser entendido com ser parte de algo, compor o todo. Nessa perspectiva, "temos o direito de sermos iguais quando a diferença nos 
inferioriza; temos o direito a sermos diferentes quando a igualdade nos descaracteriza" (BOAVENTURA, 1999, p.44)

Com efeito, o eixo basilar de escola inclusiva é entender e reconhecer que somos únicos, diferentes, logo, a educação inclusiva deve tornar as aprendizagens significativas em consonância com as características dos públicos-alvo quem se destina.

Cabe ressaltar, ainda, que uma escola inclusiva compõe uma sociedade inclusiva; esta, por sua vez, tem como fundamento o reconhecimento dos direitos de todas as pessoas, ressaltando que elas são parte integrante da sociedade. Ademais, uma sociedade inclusiva promove ações colaborativas, garante a participação, cria políticas públicas e visa acabar com a exclusão social, portanto, ela deve ser entendida e vivenciada como um princípio vital que se aplica a todas as situações do convívio social.

De acordo com a Declaração de Salamanca (UNESCO, 1994), as escolas inclusivas devem reconhecer e satisfazer as necessidades diversas dos seus alunos, adaptando-se aos vários estilos e ritmos de aprendizagem. Devem, também, garantir um bom nível de educação para todos, portanto, precisam reorganizar, construir e ressignificar os currículos, definir a organização do trabalho pedagógico, selecionar e desenvolver estratégias pedagógicas. Além disso, devem preparar e utilizar de recursos de comunicação e cooperação junto às comunidades escolares. Essas são ações essenciais para reconhecer igualmente as necessidades do público a quem a escola destina-se, bem como atuar, de forma cooperativa, para complementar um conjunto de apoios e de serviços específicos a fim de garantir o direito de uma educação com qualidade, que é a conquista coletiva dos sujeitos do processo educativo integral, contextualizado e plural.

Segundo Bolacha (2013), a educação é um processo que influencia o modo de ser, de pensar, de sentir e agir. Ela não é repetição de algumas informações estruturadas em um manual. A educação fundamenta-se na aquisição de estratégias, conhecimentos, valores, habilidades que nos tornam mais humanos, cidadãos ativos de uma sociedade complexa, entendida como:

[...] sociedades são nações-Estado, formações sociais recentes que
desempenham o papel de atores privilegiados no palco internacio-
nal. Estes atributos conferem a sociedade complexa do mundo mo-
derno, um aspecto de universalidade que, no entanto, se observado
em maior detalhe, diluísse em uma grande diversidade. Assim, as
nações-Estados, ao invés de serem algo pronto e acabado, repre-
sentam maus uma tendência ou um processo. (PEIRANO, 1983, p.
110).

Nesse sentido, a descrição da abordagem social, sustentada por uma análise do contexto concreto em que o sujeito de direito faz parte, demanda mudanças. Diante disso, a pessoa humana é chamada a acompanhar o dina- 
mismo dessas transformações e ser parte integrante dessa mudança como participante ativa, consciente e responsável pela sua construção social.

Neste contexto, o processo inclusivo visa abrir espaço de análise sobre o valor da educação como um direito social e constitui bases capazes de criar uma sociedade mais humana. Esses temas constituem focos de debate pela natureza do seu impacto na construção de uma cidadania mais consistente e visionária no seu contexto social. Portanto, construir alicerces de que o próprio mundo social serve-se, para consolidar o respeito à diferença e à valorização do outro em igual direito de oportunidades e de formação humana, é o desafio das estratégias de implementação das políticas de inclusão que Moçambique assume.

Com o intuito de despertar a consciência das pessoas, é necessário construir uma sociedade, possibilitando que todo ser humano, independentemente das suas diferenças, físicas, intelectuais, étnicas possa ser protagonista no mundo em que todos fazem parte, usufruem dos mesmos direitos e oportunidades.

\section{Sistema educativo em Moçambique pós independência}

O processo educativo em Moçambique foi resultado de uma evolução histórica das transformações ocorridas no período de transição do país do sistema colonial para o sistema pós-colonial. Ele trouxe uma nova visão sobre o futuro de Moçambique no que consiste à educação para todos.

O processo educativo em Moçambique teve como base três instrumentos como marco legal que fizeram com que o governo de Moçambique pudesse construir um Sistema Nacional de Educação (SNE) capaz de responder aos desafios das mudanças do país, desde 1975 até hoje. Esses instrumentos são os fundamentos legais que marcaram as fases de regulamentação jurídica do Sistema Nacional de Educação em Moçambique pós-independência regulamentadas pela Lei $n^{\circ} 4 / 83$, de 23 de março, Lei $6 / 92$ de 6 de maio e a Lei n. ${ }^{\circ} 18 / 2018$ de 28 de dezembro.

A lei do Sistema Nacional de Educação é o instrumento jurídico que estabelece os fundamentos, princípios e objetivos da educação na República de Moçambique. Historicamente, as reformas educacionais ocorridas em Moçambique desde a Independência Nacional (1975), fato que se tornou um marco na organização política do país, podem ser divididas em dois grandes períodos: o período antes de independência e o período pós independência. Cada um desses períodos está dividido em momentos marcados por transformações sociais, políticas, econômicas e ideológicas que se caracterizam, por um lado, pela imposição de uma ordem social e cultural hegemônica e a negação das estruturas tradicionalmente existentes e, por outro, pela luta na tentativa da ruptura e superação para a implantação de uma nova ordem 
social. Essas transformações vêm sendo construídas com contradições e conflitos próprios de processos de busca de identidade de modo direto ou indireto os quais impactam na compreensão das políticas internacionais, que orientam as reformas educacionais moçambicanas.

A educação antes da independência, em 1975, era considerada um serviço destinado para uma determinada classe de pessoas, logo, tinha um caráter discriminatório. O objetivo central desse sistema de educação era despersonalizar os moçambicanos, inculcando-lhes valores culturais e cívicos portugueses.

Antes da independência, havia dois tipos de escolas: uma para os fiIhos dos negros ou "indígenas" e outra para os filhos dos brancos e assimilados. Segundo Golias (1993), eram considerados assimilados todos aqueles moçambicanos que se adaptavam à cultura portuguesa. Já os que não se adaptavam eram considerados indígenas, portanto, o sistema de educação colonial estava dividido em dois subsistemas distintos, "um oficial destinado aos filhos dos brancos e assimilados e o outro Indígena destinado aos pretos". (GOLIAS, 1993, p. 31). O sistema educacional visava impedir a população moçambicana de ter acesso à educação para todos e com isso impedia que alcançassem postos de trabalho de maior qualificação técnico-profissional, fato que impactava no não acesso a outros direitos assegurados.

A transição do sistema do período educativo colonial para uma de educação moçambicana dá-se com a nacionalização do ensino, por meio do Decreto 12/75 de 6 de setembro de 1975, que proíbe o exercício a título privado da atividade de ensino em Moçambique, passando essa atividade a ser exclusiva do Estado. Dada à necessidade de Moçambique reconstruir-se como uma nação em que todos têm o direito e oportunidades iguais no processo de ensino, o Estado com uso deste instrumento procurou redimensionar a educação como um valor social para todos.

Para Golias (1993, p. 233), "a nacionalização da educação constituiu o primeiro passo para o Estado dirigir o processo educativo e uniformizar o sistema de ensino, em suma, para democratizá-Io". Com a nacionalização do ensino, a gestão do sistema educativo foi confiada, única e exclusivamente, ao Ministério da Educação e Cultura de Moçambique (MECM). Foi nesse contexto que a educação tornou-se socialmente um direito e dever de cada cidadão, como um elemento para o rompimento das desigualdades sociais. Dessa forma, a educação aparece como a garantia de igualdade do acesso escolar para todos, possibilitando assim a planificação da ação educativa com vista à criação de um novo sistema de educação. 


\section{Educação como instrumento de humanização e sociali- zação inclusiva}

Em termos gerais, as definições de educação apresentadas por diferentes autores, embora possam parecer díspares, geralmente têm pontos em comum, particularmente quando colocam o indivíduo como sujeito no centro de atividade que se caracteriza como um processo que capacita, transforma e influencia as pessoas para interagir com o meio.

Brandão (1986) afirma que educação é todo conhecimento adquirido com a vivência em sociedade, seja ela qual for. Para ele, não existe um modelo nem uma única maneira para se educar, uma vez que a educação ocorre a partir do momento em que se observa, entende, imita e aprende-se. Este processo não ocorre somente dentro de uma sala de aula onde existe um professor formado para educar. Em todos os povos, em todas as classes, a aprendizagem está presente, de várias maneiras.

Na visão de Muniz (2002), a educação deve cultivar a moral, despertando para que o homem tome consciência de que ela deve estar presente em todas as ações de sua vida, em todo o seu desenvolvimento, em todo o ser e, por efeito, deixando raízes sobre o direito, que não subsiste sem a moral.

Zacharias (2007), por sua vez, afirma que educar é construir; é libertar o homem do determinismo, passando a reconhecer o papel da história e a questão da identidade cultural, tanto em sua dimensão individual como social.

Já a concepção de educação de Paulo Freire (2014) reconhece o homem como ser autônomo. Esta autonomia está presente na definição de vocação antológica de "ser mais" que está associada com a capacidade de transformar o mundo.

Na Constituição Moçambicana de 2004, a educação é um direito social, porém, é importante explicitar que, na Constituição de Moçambique, a educação é aquela que se encontra indicada dentro dos parâmetros constitucionais, ou seja, que é feita conforme o disposto no Artigo 113, § 1 da Constituição da República de Moçambique, a qual indica que a República de Moçambique promove uma estratégia de educação visando à unidade nacional, a erradicação do analfabetismo, o domínio da ciência e técnica, bem como a formação moral e cívica dos cidadãos.

Neste sentido, a tarefa da educação é formar para uma cultura cidadã, democrática com princípios de igualdade para viabilizar a cidadania. A integração das tarefas e sua materialização são, então, determinadas pelo imperativo categórico da ética. A educação, enquanto formação de cidadãos traz a responsabilidade de situar os cidadãos como sujeitos histórico-políticos, capazes de conscientemente operar mudanças significativas em toda a realidade social. A ação educativa deve não só proporcionar à pessoa o conta- 
to como diversos modelos de pensamento e de comportamento cívico, mas também incentivá-la a saber fazer escolhas na vida, as quais configuram desejos, necessidades, preocupações e aspirações. Em outras palavras, podemos dizer que esses contatos que a pessoa tem com a realidade vivencial configuram e exprimem a personalidade humana.

Como se vê, a educação tem o papel de fazer com que as pessoas sejam conscientes da realidade vivida, com o intuito de transformar para o bem comum. Por meio dos processos educativos, a pessoa aprende a ser e a conviver de forma mais justa e humana.

\section{Processo de implementação das estratégias internacio- nais de inclusão em Moçambique}

De acordo com a realidade mundial, Moçambique é um país em que a abordagem sobre inclusão e educação inclusiva constitui impacto que estes processos têm na vida social e política de um país. Moçambique, tal como outros países signatários da Declaração Universal dos Direitos Humanos DUDH (1948), reconhece que todos os seres humanos nascem livres e iguais em dignidade e direitos. À luz desse documento, o país tem o dever de defender e promover os direitos fundamentais da pessoa humana.

Tomamos como direitos humanos toda construção histórica, expressão dos resultados de lutas pelo reconhecimento e realização da universalização da dignidade humana, por serem construídos em contextos sociais e políticos e, acima de tudo, por disseminar a emancipação, a liberdade, a igualdade, a cooperação, a tolerância e a paz, atitudes para incorporar o interesse público, isto é para todos.

Reconhecer o direito à educação como essencial pelos moçambicanos constitui um desafio do Estado para a sua implementação; para tanto, faz-se necessário reconhecer e potencializar as demandas da população escolar, caracterizadas por algum tipo de deficiência, como, por exemplo, limitação linguística, aprendizagem, econômica, cultural e/ou social.

Em 1998, o Ministério da Educação de Moçambique assumiu, com o apoio da UNESCO, o projeto denominado "Escolas Inclusivas", com o objetivo de combater a exclusão e promover a escolaridade para todos. Para materialização desta política de inclusão, Moçambique estabeleceu, na Constituição da República (CRM, 2004), que a educação constitui direito e dever de cada cidadão e o Estado tem a responsabilidade de promover a extensão da educação à formação profissional continuada, bem como a igualdade de acesso de todos os cidadãos ao gozo deste direito tal como ditam os $\S \S 10$ e 20 do Art. ${ }^{\circ} 88$ da Constituição da República de Moçambique. Com efeito, o Estado 
serve-se de instrumentos legais que promovem as políticas de inclusão, tanto no sistema educacional como nos diversos segmentos sociais.

Porém, o entendimento da educação como um direito perpassa a compreensão de um projeto educativo, que tem como fim a formação para a cidadania, por meio da ciência, da emancipação, da liberdade, da razão e do pensamento crítico. Logo, a sociedade passa a se organizar e agir de modo participativo, expressando a soberania popular, isto é, a educação como um direito transforma a vida de uma sociedade tornando-a democrática em sua essência.

No âmbito de reajustamento do sistema educativo, face às políticas internacionais de inclusão escolar, Moçambique busca implementar as suas regulamentações e políticas educacionais, de acordo recomendações e estratégias internacionais, as quais são subsidiadas pela Declaração Mundial sobre a Educação para Todos (UNESCO, 1990), Declaração de Montreal (França, 1999), Declaração sobre Direitos das Pessoas com Deficiência (ONU, 2006), a Carta para o Terceiro Milénio (1999), Declaração de Dakar (2000) em que Moçambique é também signatário. Todos esses documentos estão em acordo com a Constituição da República (MOÇAMBIQUE, 2004), a Lei do Sistema Nacional de Educação (MOÇAMBIQUE, 1994) e com a Declaração de Salamanca assinada e divulgada em 1994. Moçambique adota as políticas internacionais de inclusão no sistema educativo quatro anos depois, contemplando os princípios da não discriminação, a busca da igualdade de direitos e a equidade nos processos de educação para todos

A partir de 1998, em Moçambique, Escolas Inclusivas são entendidas como espaços que se movimentam para reorganizar seus processos formativos, desde sua estrutura organizacional. Tais movimentos demandam mudanças no currículo, na eliminação de barreiras físicas, atitudinais e procedimentais. Demandam também a formação continuada dos professores, com foco na percepção das aprendizagens e na maneira de ensinar, com o intuito de atender as especificidades de cada estudante. Essa proposta de escolas inclusivas foi introduzida na rede educacional em Moçambique gradualmente, sendo que a $1^{\text {a }}$ fase envolveu 11 (onze) escolas, tendo como fundamento que "todos os alunos devam aprender juntos, sempre que possível, independentemente das dificuldades e das diferenças que apresentam", como recomenda a Declaração de Salamanca (UNESCO, 1994).

Para o período entre 1998 a 2003, o Ministério de Educação de Moçambique traçou um plano estratégico (PEE 1998-2003), sendo o instrumento oficial para a implementação das políticas de educação, tendo como base de apoio o Plano Nacional de Educação. Esta ferramenta reforça os compromissos que o governo assume no que tange à educação para todos, quando é signatário de políticas internacionais. Ela apresenta para o Estado o lema 
"Combater a Exclusão, Renovar a Escola", ao mesmo tempo que divulga o Plano Estratégico de Educação com três principais objetivos para o sistema educativo.

No que tange ao primeiro objetivo, vale ressaltar que ele consistia em aumentar o acesso às oportunidades educativas para todos os moçambicanos, em todos os níveis do sistema. O segundo objetivo era manter e melhorar a qualidade da educação, entendida como universalização, acesso, permanecia e garantia de acesso a outros direitos. Já o terceiro consistia em desenvolver um quadro institucional e financeiro para gerar no futuro a sustentabilidade das escolas e manter os alunos moçambicanos.

Por outro lado, o sucesso da implementação da estratégia exigiu uma estreita colaboração entre o Ministério da Educação e uma gama de grupos de interesse em relação ao sistema educativo, incluindo a comunidade escolar, as famílias, a comunidade local, empregadores, ONG's e confissões religiosas, os quais foram chamados a assumir papeis significativamente a respeito do financiamento e gestão da educação. A permanência do apoio financeiro por parte dos parceiros internacionais de Moçambique, para se garantir a educação no país, ainda é uma realidade.

Segundo o Plano Estratégico de Educação, o Estado reafirma que o objetivo último é o de apoiar a estratégia de desenvolvimento nacional do Governo, através da construção de um sistema educativo que proporcione aos cidadãos moçambicanos os conhecimentos e habilidades de que irão precisar para obterem meios de sobrevivência sustentáveis, acelerarem o crescimento da economia e reforçarem as instituições de uma sociedade democrática. Apesar dessa ousadia de se projetar para o futuro, o Ministério da Educação reconhece sua limitada capacidade de financiamento e administração e usa, como estratégia de implementação das políticas públicas, a busca de parceiros nacionais e internacionais para se cooresponsabilizarem em atingirem as metas por ele estabelecidas.

Quanto à educação especial, entendida como uma modalidade de ensino, o Ministério da Educação descreve, no Plano Estratégico de Educação (1998-2003), que se faz necessário expandir oportunidades educativas para crianças com necessidades especiais, que são aquelas crianças que sofreram, durante a guerra, traumatismos físicos e emocionais, que lhes impediram de frequentar a escola ou diminuíram a sua capacidade de aprenderem em salas de aula tradicionais. As crianças veem limitadas as suas oportunidades de aprendizagem porque o seu acesso escolar é limitado, ou porque os programas e os serviços que podem responder às suas necessidades não estão amplamente disponíveis. A implementação do processo de inclusão no sistema educativo exige um trabalho árduo de construção das relações sociais de todas as crianças na escola como um dos maiores fundamentos à ampliação de 
intervenção de práticas educativas.

Segundo Rodrigues (2008), por meio da Declaração de Salamanca de 1994, pode-se observar que o respeito às características, interesses e capacidades de aprendizagens que são próprios do público a que se destina a educação inclusiva, demonstra que os sistemas educativos devem ser projetados e desenvolvidos com vistas a diferentes predicados e indigências. Por meio da mesma Declaração, ficou evidenciado que as pessoas, com necessidades educativas especiais de aprendizagens, devem ter acesso às escolas comuns, que deverão integrá-las numa pedagogia centralizada na criança, capaz de atender as necessidades. Podemos reafirmar que o processo de inclusão pressupõe tratar de questões relacionadas à diferença, levando em conta a sociedade atual que é diversa, plural, e que deve respeitar as diferenças como características. Pensar a diferença hoje é reestruturar práticas sociais, priorizando a dignidade humana.

Na visão de Rodrigues (2006), o conceito de Inclusão, no âmbito específico da Educação, implica rejeitar, por princípio, a exclusão (presencial ou acadêmica) de qualquer aluno da comunidade escolar. Para isso, seguir uma política de educação inclusiva é promover, defender e garantir políticas, culturas e práticas que valorizem a colaboração de cada pessoa para a construção de um conhecimento partilhado e, desta forma, alcançar a qualidade acadêmica e sociocultural, sem discriminação.

Em Moçambique, a publicação pelo Ministério da Educação e Desenvolvimento Humano (2012), do documento denominado Plano Estratégico de Educação (PEE, 2012-2016), descreve que o governo, por meio do Ministério de Educação, pretende promover o direito de todas as crianças, jovens e adultos à educação básica, incluindo aquelas que apresentam limitações físicas e/ou de aprendizagem e, portanto, necessitam de uma atenção educativa especial. A estratégia assenta-se no princípio da inclusão, descrita nas políticas internacionais, pois visa assegurar que as crianças, os jovens e os adultos com necessidades educativas especiais e/ou com deficiência possam frequentar em escolas regulares.

\section{Marco legal sobre educação inclusiva em Moçambique}

A implementação do conceito de escola inclusiva exige o desenvolvimento de competências e habilidades dos profissionais da educação para lidar com diferentes características físicas e cognitivas dos estudantes. Uma Educação Inclusiva, como concepção de educação, requer processos de ensino-aprendizagem centrados no aluno. Ao mesmo tempo, é necessária uma atenção especial à infraestrutura da escola, para que se possa garantir e promover a participação de todos os alunos. A abordagem da Educação Inclusiva 
para a diversidade deve estar em todas as políticas e regulamentos que orientam a (gestão da) Escola e a formação de professores para todos os subsistemas e níveis de ensino.

Em seu sistema educacional, Moçambique tem um elenco de instrumentos legais, que busca efetivar a abordagem inclusiva, Lei 4/83 de 23 de março, que enfatizou o direito à educação e à erradicação do analfabetismo e da pobreza, bem como a introdução da escolaridade obrigatória, principalmente na frequência e conclusão do ensino primário e universal para crianças que completassem 7 anos de idade.

A Resolução n. 8/95, de 22 de agosto, aprova o Plano Nacional de Educação e a respectiva Estratégia de implementação. Já a Lei 6/1992, de 6 de maio, Lei do Sistema Nacional da Educação, aborda os diversos níveis de escolarização, bem como a sua estrutura e organização. Essa lei sublinha ainda que a Educação é um direito e dever de todos os cidadãos e destaca a necessidade de integração dos alunos com deficiência dentro das escolas regulares. $O$ Decreto 58/2008, de 30 de dezembro, por sua vez, aprova o Regulamento de Construção e Manutenção dos dispositivos técnicos de acessibilidade, circulação e utilização dos sistemas dos serviços públicos às pessoas com deficiência ou de mobilidade condicionada

Há que se mencionar, também, o Plano Nacional de Ação para Deficiência (PNAD), que é um documento estratégico que estabelece as ações prioritárias para a área de deficiência, e a Política de Ação Social, que estabelece as linhas gerais da política e estratégia do Governo, sobre as questões da Ação Social do país, as quais incluem questões ligadas à deficiência e à criança no geral.

Cabe apontar, ainda, a Lei no 18/2018, de 28 de dezembro, do Sistema Nacional de Educação, que, no abrigo dessa nova Lei do Sistema Nacional de Educação (SNE), aprova consensualmente a escolaridade obrigatória no país, que passa a ser da $1^{\mathrm{a}}$ a $9^{\mathrm{a}}$ classe, trazendo um novo modelo que altera o atual, introduzido pela Lei n. ${ }^{\circ} 6 / 92$, de 6 de maio, que estabeleceu a escolaridade obrigatória da 1. a a 7. classe. Entre outras alterações, consiste na redução do ensino primário de 7 para 6 classes, com um plano curricular contínuo e em

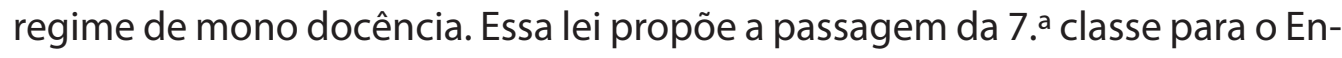
sino Secundário Básico que, por sua vez, passa a ser de apenas 9 classes, com caráter obrigatório, para que todas as crianças do país concluam o nível em tempo útil. Determina que as crianças devem ser obrigatoriamente matriculadas na primeira classe no ano em que completam 6 anos de idade. Estabelece também que a frequência do Ensino Primário é gratuita nas escolas públicas. Visa reajustar este instrumento ao atual contexto social, político e econômico, garantindo uma educação equitativa e inclusiva, bem como a modernização e ajustamento da sua estrutura de funcionamento. 


\section{Desafios do sistema educativo inclusivo em Moçambique}

Apesar de todos os instrumentos legais, a concretização do processo inclusivo, no sistema de educação do país, configura-se como um grave problema devido à não materialização das políticas estabelecidas. Esse problema é causado pela ausência do que está recomendado, previsto e/ou determinado, no que se refere a sua estrutura física, curricular e humana, para atender, de modo qualificado, os estudantes que estão em processo de inclusão. A limitação de oportunidades dificulta o processo de aprendizagem, evidenciando a desigualdade e a discriminação.

Nas escolas de Moçambique, a estrutura física é inadequada e os recursos humanos com formação são escassos. Essas deficiências podem ser consideradas como elementos limitadores para efetivação das políticas de inclusão escolar recomendadas pelo Estado na tentativa de responder às recomendações internacionais.

Por outro viés, ao analisar as propostas pedagógicas elaboradas pelas escolas, como ferramentas para o ensino e aprendizagem de todos, percebe-se que não são contempladas as necessidades dos estudantes em relação as suas características. Verifica-se a ausência de adaptação curricular, de recursos de comunicação e/ou didáticos. Além disso, a não correspondência das demandas educativas impossibilita o acesso pleno à educação, negando a formação cidadã como princípio da organização social democrática que vem sendo construída em Moçambique.

Em face de exiguidade de recursos, o Ministério da Educação e Desenvolvimento Humano (MINEDH) reconhece que os esforços empreendidos pelo Governo ao acesso a esse tipo instrução, ainda está aquém do desejado, mormente a de alunos com necessidades educativas especiais de aprendizagens.

Por outro lado, os desafios impostos ao Estado são a formação continuada de professores, a transformação dos estabelecimentos de ensino em verdadeiros locais de satisfação de necessidades educativas para todos os alunos, potencializando os conhecimentos, habilidades, valores e atitudes com vista à sua integração na vida social, econômica e política.

De acordo com Rosa (2004), é necessário que a sociedade seja aberta a todos, estimule a participação de cada um e valorize as experiências humanas, reconhecendo o potencial de todos os cidadãos. Também é necessário que ela ofereça oportunidades iguais para que cada pessoa seja livre e tenha autodeterminação, independente das suas características, logo, deve ser inclusiva. 


\section{Propostas de implementação das políticas de inclusão no sistema educativo em Moçambique}

Em Moçambique, a educação inclusiva é uma realidade quanto a sua organização legal, porém, o grande desafio consiste em implementar, efetivamente, as estratégias e ações inclusivas coordenadas para a melhoria da vida e da convivência social.

O Plano Nacional de Ação para Área de Deficiência II 2012-2019 (PNAD II), publicado pelo governo de Moçambique, apela claramente para a educação inclusiva como uma estratégia de educação de pessoas com deficiência em todos os níveis e subsistemas do sistema educativo, tanto para crianças e para jovens e adultos.

Na opinião de Werneck (1999), para a construção de uma escola livre de preconceitos, a inclusão educacional deve atuar no sentido de favorecer a convivência com a diversidade e instituir o respeito e a fraternidade entre as pessoas.

A escola inclusiva para a autora deve promover o convívio com as diferenças, o que deve ser estimulado desde a mais inicial das formas de convivência social na educação da primeira infância, espaço que as crianças se encontram pela primeira vez. A partir do momento em que se favorece o convívio com a diversidade, constrói-se cidadania, sendo o modo eficaz de combater o preconceito e oportunizar a compreensão da diversidade.

Nesse sentido, a educação inclusiva é uma possibilidade de tornar as pessoas mais empáticas, respeitosas, críticas e tolerantes, construindo os valores dos direitos humanos ativos em suas vidas, de modo a conferir a igualdade, a justiça, a liberdade e a paz, como elementos essenciais para efetivação de sociedade mais justa.

\section{Considerações}

As transformações engendradas para construir uma sociedade inclusiva em que o homem é um sujeito ativo capaz de desenvolver o seu meio social por meio da educação escolar, perpassam o entendimento dos direitos da sua formação baseados nos fundamentos éticos e nos valores que nos tornam humanos, justos e dignos. Sabe-se que o processo educacional inclusivo, a partir dos valores dos direitos humanos, impõe vivências na realidade que promovem a igualdade, a fraternidade, a tolerância, a cooperação e a paz.

É por meio das práticas inclusivas que se efetivam os direitos humanos, sendo materializadas pelas políticas públicas implementadas pelo Estado. Portanto, o processo educativo inclusivo, com vista à formação integral do cidadão, constituirá a base de sustentabilidade para o exercício da cidadania, 
que se reflete no individuo ético, capaz de aprender para a autonomia, que coopera e participa da vida pública.

Para que a educação possa contribuir com a construção de uma sociedade democrática, com identidade inclusiva, é necessário enfatizar a centralidade nas pessoas, nos aspectos culturais, cognitivos, afetivos, sociais e históricos presentes nas organizações que compõem o Estado.

Dessa forma, os conhecimentos oriundos da implementação das políticas internacionais de inclusão podem ser entendidos como limitações das recomendações internacionais, já que estas não contemplam a realidade, restringem direitos e impossibilitam a realização de projetos emancipatórios. Apesar de reconhecerem as demandas de uma agenda internacional, as políticas internacionais de inclusão não vislumbram o desenvolvimento humano por falta entendimento conceitual, recursos econômicos e, por vezes, como prioridades para o Estado.

Ao defender a educação como uma ferramenta de implementação das políticas internacionais, à medida que revela ao homem os valores que o conduz a viver em sociedade como ator do seu destino, portanto as políticas públicas deslocam a perspectiva inclusiva para centralidade das lutas quotidianas por direitos e pela garantia daqueles que já existem. Esses direitos e essas garantias vêm plasmados nos instrumentos jurídicos de Moçambique, orientados pelos acordos internacionais, que servem de base de sustentação na promoção de valores e oportunidades iguais.

Das constatações resultantes da análise de conteúdo dos documentos que compuseram este estudo, pode-se afirmar que a implementação das políticas de promoção de educação para todos no país causou, em Moçambique, uma explosão de acesso aos processos escolares, caracterizadas por um expressivo aumento do número de alunos, professores e a criação de uma considerável rede de infraestruturas escolares. Apesar disso, o problema da expansão e cobertura da rede escolar para todos continua a ser um desafio para o próprio Estado.

Por outro lado, o reconhecimento de que as estratégias internacionais que as políticas dos Estados promovem a educação inclusiva avançam como direito. E os Direitos Humanos constituem a seara da condição humana, entendidos em sua plenitude, materializando-se em diferentes dimensões e formas, deve-se compor cada vez mais as pautas de agendas políticas dos governos, instituições sociais e das práticas comunitárias. Dessa forma, a definição de estratégias para implementar práticas inclusivas são fundamentais para que os direitos humanos se traduzam em exercício do cotidiano. 


\section{Referências}

BOLACHA, N.F. A mulher moçambicana na ocupação de cargos de decisão: um estudo de caso no âmbito das direções provinciais de Nampula. 2013. 220p. Tese (Doutorado em Ciências da Educação) - Universidade Católica Portuguesa. Lisboa, 2013.

BRANDÃO, C.R. O que é educação. São Paulo: Ed. Brasiliense, 1986.

BUENO, J. G. Inclusão escolar: uma crítica conceitual e política. Trabalho apresentado no V Seminário Capixaba de Educação Especial, 2005.

CHAMBAL, L. A. Os Processos de escolarização dos alunos com necessidades educativas especiais em Moçambique. 2007. Dissertação. (Mestrado em Educação) - Pontifícia Universidade Católica de São Paulo. São Paulo, 2007.

FREIRE, P. Educação como prática da liberdade. 36. ed. São Paulo: Paz e Terra, 2014.

GOLIAS, M. Sistemas de ensino em Moçambique. Editora Escolar. Maputo, 1993, p.31.

HOBBES, T. Do cidadão. São Paulo: Martins Fontes, 2002.

MINISTERIO DA EDUCAÇÃO E CULTURA. Plano Estratégico de Educação e Cultura (2006-2011). Maputo, 2006. Disponível em: http://www.mined.gov. mz. Acesso em: 23 jul. 2020.

MINISTERIO DA EDUCAÇÃO E CULTURA. Plano Estratégico de Educação e Cultura (2011-2016). MEC. Maputo, 2010. Disponível em: http://www.mined. gov.mz. Acesso em: 23 jul. 2020.

MOÇAMBIQUE. Constituição da República de Moçambique. Maputo: Imprensa Nacional, 2004. Disponível em http://www.mined.gov.mz/Documents/ Políticas\%20Educacionais.pdf. Acesso em: 23 jul. 2020.

MUNIZ, R. M.F. O direito à educação. Rio de Janeiro: Renovar, 2002.

PEIRANO, Marisa G. S. Etnocentrismo às avessas: o conceito de sociedade complexa. Ethnocentrisme à rebours: le concept de Société Complexe). 
Dados, Rio de Janeiro, v. 26, n. 1, p. 97-115, 1983.

REPÚBLICA DE MOÇAMBIQUE. Lei6/92. Maputo:1992, I Série, n. 19. Disponível em: http://www.mined.gov.mz. Acesso em: 23 jul. 2020.

REPÚBLICA DE MOÇAMBIQUE. Plano Estratégico de Educação (PEE, 20122016). Maputo, 2011 Disponível em: http://www.mined.gov.mz. Acesso em: 23 jul. 2020.

REPÚBLICA DE MOÇAMBIQUE. Plano Nacional de Ação para Área de Deficiência II 2012-2019 (PNAD II). Maputo, 2011. Disponível em: http://www. mined.gov.mz. Acesso em: 23 jul. 2020.

REPÚBLICA POPULAR DE MOÇAMBIQUE. Lei 4/83. Maputo,1983, I Série N. 12. Disponível em: http://www.mined.gov.mz. Acesso em: 23 jul. 2020.

ROSA, S. P. S. Fundamentos teóricos e metodológicos da inclusão. Curitiba: IESDE, 2004

REPÚBLICA DE MOÇAMBIQUE. Plano Estratégico de Educação e Cultura 20122016, Maputo: MEC, 2012. Disponível em: http://www.mined.gov.mz. Acesso em: 23 jul. 2020.

REPÚBLICA DE MOÇAMBIQUE. Decreto 53/2008 de 30 de dezembro: Maputo: MEC 2008. Disponível em: http://www.mined.gov.mz. Acesso em: 23 jul. 2020.

RODRIGUES, D. Questões preliminares sobre o desenvolvimento de políticas de educação inclusiva. Revista Inclusão, Brasília, SEESP/MEC, 2008, v. 4, n. 1, p. 33-40.

RODRIGUES, David. Inclusão e educação: doze olhares sobre a educação inclusiva. Grupo Editorial Summus, 2006.

ROUSSEAU, Jean Jacques. Do contrato social princípios do direito político. Traduzido por José Cretella Junior e Agnes Cretella. São Paulo: Revista dos Tribunais, 2003.

SANTOS, Boaventura de Sousa. A Construção Multicultural da lgualdade e da Diferença. Oficina do CES, n. 135, 1999. Publicação seriada do Centro de 
Estudos Sociais. Colégio São Jerónimo, Coimbra. Disponível em: http://www. ces.uc.pt/publicacoes/oficina/135/135.pdf. Acesso em: 28 jan. 2020.

UNESCO. Conferência Mundial De Educação Para Todos. Declaração Mundial Sobre Educação Para Todos. Jomtien, 1990. Disponível em: https://www. unicef.org/brazil/declaracao-mundial-sobre-educacao-para-todosconferencia-de-jomtien-1990. Acesso em: dez. 2020

UNESCO. Conferência Mundial Sobre Necessidades Educativas Especiais: Acesso E Qualidade. (1997). Declaração De Salamanca, E Linha De Ação Sobre Necessidades Educativas Especiais. Brasília: CORDE, 1998. Disponível em: http://portal.mec.gov.br/seesp/arquivos/pdf/salamanca.pdf. Acesso em: dez. 2020

WERNECK, H. Prova, provão. Camisa de força da educação. Petrópolis, RJ: Vozes, 1996.

ZACHARIAS, Vera Lúcia C. Paulo Freire e a educação. Centro de Referência Educacional, 2007.W

Recebido em: 11 de dezembro de 2020.

Aprovado em: 30 de abril de 2021. 